\title{
Detoxifying $\mathrm{CO}_{2}$ Capture Reclaimer Waste by Anaerobic Digestion
}

\author{
Shuai Wang • Jon Hovland • Steven Brooks • \\ Rune Bakke
}

Received: 31 July 2013 / Accepted: 3 October 2013 /

Published online: 13 October 2013

(C) The Author(s) 2013. This article is published with open access at Springerlink.com

\begin{abstract}
The decrease in toxicity of carbon capture reclaimer monoethanolamine (MEA) waste (MEAw) during anaerobic degradation of such waste together with easily degradable organics was investigated. Samples were collected from a bioreactor at steady state with $86 \%$ organic chemical oxygen demand removal at room temperature, which had been running on MEAw for 2 years. The toxicity of the digester effluents were 126, 42 and 10 times lower than that of the MEAw to the tested freshwater trophic groups of Pseudokirchneriella subcapitata, Daphnia magna and embryos of Danio rerio, respectively. The toxicity of the tested taxonomic groups after anaerobic digestion was mainly attributed to the ammonia generated by the degradation of MEAw.
\end{abstract}

Keywords Amine waste $\cdot$ Anaerobic digestion $\cdot \mathrm{CO}_{2}$ capture $\cdot$ Detoxify $\cdot$ Toxic effect

\section{Introduction}

Carbon capture and storage (CCS) is a technology proposed in energy intensive industries (e.g. power plant) to mitigate greenhouse gas effects [1]. Large scale CCS plants will generate potentially hazardous contaminates such as solvent and solvent degradation products. Life cycle assessment has shown that CCS systems can achieve a significant reduction in greenhouse gas emissions, although there are multiple environmental trade-offs to consider, such as increased human and environmental toxicity potential [2].

The CCS solvents that are normally used include monoethanolamine (MEA), methyldiethanolamine (MDEA), etc., which can cause environmental harm [3]. Complex solvent degradation products are generated in CCS process due to solvent reaction with flue gas impurities, thermal degradation, etc. and are difficult to qualify and quantify [4, 5]. Corrosion inhibitors added to increase the durability, and effectiveness of amine solvents can be resilient to biodegradation [6]. MEA waste from CCS is a complex mixture of solvent, MEA degradation products, substances other than $\mathrm{CO}_{2}$ captured from the flue gas, corrosion inhibitors and corrosion products. The amine waste arises as the bottom product from the distillation unit when thermal reclaiming

S. Wang $(\bowtie) \cdot J$. Hovland $\cdot$ S. Brooks $\cdot$ R. Bakke

Porsgrunn, Norway

e-mail: wang.shuai@hit.no 
of the solvent is used. According to EU regulations and directives [7], the waste is classified as hazardous waste in accordance with hazardous waste Directive 91/689/EEC [8]. Anaerobic digestion $(\mathrm{AD})$ that combines assimilating and degrading organics and recovering energy (in the form of methane) is a promising amine waste treatment method investigated [9-11].

The aim of the presented research was to investigate the detoxifying effect of AD treatment on MEA reclaimer waste (MEAw) collected from a coal fired power plant. A hybrid anaerobic reactor with an adapted culture that has been treating MEAw together with an easily degradable co-substrate since $2010[9,10]$ was employed and operated at steady state when effluent samples were collected for toxicity assessments. The freshwater toxicity of this treated waste (TW) was compared to toxicity of pure MEA and MEAw by using standard regulatory Organisation for Economic Co-operation and Development (OECD) bioassays [12] for the unicellular algae Pseudokirchneriella subcapitata, the freshwater crustacean Daphnia magna, and the embryos of the zebra fish Danio rerio. The effect concentration (EC) endpoints causing $50 \%$ growth reduction, acute immobilisation and morality, respectively, were compared.

\section{Material and Methods}

Anaerobic Digestion

Feed

The MEAw used in this study was the waste product of the MEA solvent distillation from the 'reclaimer unit' in a full scale $\mathrm{CO}_{2}$ capture plant treating flue gas from a coal fired power plant boiler. The MEA concentration in the MEAw applied here was $18 \mathrm{wt} \%$. Nitrogen content was about $10 \mathrm{wt} \%$. The measured MEAw chemical oxygen demand (COD) was $630 \mathrm{mg} \mathrm{COD} / \mathrm{g}$ MEAw. Other components in the waste were not quantified but information for similar waste types can be found in $[4,5,13]$.

Easily degradable organics were applied as co-substrate (41\% of feed COD) together with MEAw (59\% of feed COD) as the feed for the anaerobic digester. The co-substrate was used to provide necessary nutrients, minerals and easily degradable organics to maintain biomass that can tolerate exposure to toxic and inhibitory chemicals from the MEAw and to increase the relatively low carbon to nitrogen ratio in the MEAw that could otherwise inhibit microorganisms, especially methanogenesis $[9,10]$. Properties and quantities of the cosubstrate are shown in Table 1.

Anaerobic Reactor and Inoculums

Detailed information about the applied lab-scale hybrid anaerobic digester (Fig. 1) and the feed scenarios used for the long-term culture adaptation are given in [9].

\section{Experimental Management}

The anaerobic digester was operated at $22 \pm 2{ }^{\circ} \mathrm{C}$. Feed substrate used in the anaerobic digester is shown in Table 1. Feed solutions were prepared by mixing the MEAw and co-substrate in deionized water and stored at $4{ }^{\circ} \mathrm{C}$ before use. Buffer $\left(0.15 \mathrm{~g} / \mathrm{L} \mathrm{K}_{2} \mathrm{HPO}_{4}\right.$ and $\left.0.15 \mathrm{~g} / \mathrm{L} \mathrm{KH}_{2} \mathrm{PO}_{4}\right)$ was added in the prepared feed solution. The feed $\mathrm{pH}$ was 10 . The feed substrate was pumped in to the reactor by a peristaltic pump semi-continuously at a feed speed of $11 \mathrm{~mL} / \mathrm{min}$ for $8 \mathrm{~min}$ a 
Table 1 Compositions of the feed substrate

\begin{tabular}{lccl}
\hline Component & Concentration $(\mathrm{g} / \mathrm{L})$ & COD $(\mathrm{g} \mathrm{COD} / \mathrm{L})$ & Nitrogen concentration $(\mathrm{g} / \mathrm{L})$ \\
\hline Glucose & 1.7 & 1.8 & 0.0 \\
Yeast extract & 3.6 & 3.3 & $0.4^{\mathrm{a}}$ \\
Peptone & 3.0 & 4.5 & $0.4^{\mathrm{b}}$ \\
MEA waste & 22.0 & 13.9 & $2.2^{\mathrm{c}}$ \\
Total & 30.3 & 23.5 & 3.0
\end{tabular}

${ }^{a}$ Product reference shows a nitrogen concentration of $10.5 \%$ in this yeast extract

${ }^{\mathrm{b}}$ Product reference shows a nitrogen concentration of $12-13 \%$ in this peptone, and $12.5 \%$ was used in this calculation

${ }^{\mathrm{c}} \mathrm{A}$ fraction of $10 \mathrm{wt} \%$ of MEAw was used here

day at eight different times. A hydraulic retention time (HRT) of 14 days was maintained. The applied feed organic loading rate (OLR) was $1.6 \mathrm{~kg} \mathrm{COD} \mathrm{m}^{-3}$ day $^{-1}$ in the test period. Effluents were collected for $\mathrm{pH}$, ammonia and COD measurements. Effluents for the toxicity test were collected when steady state reactor performance was observed. The analytical methods, except the toxicity tests, are given in [9].

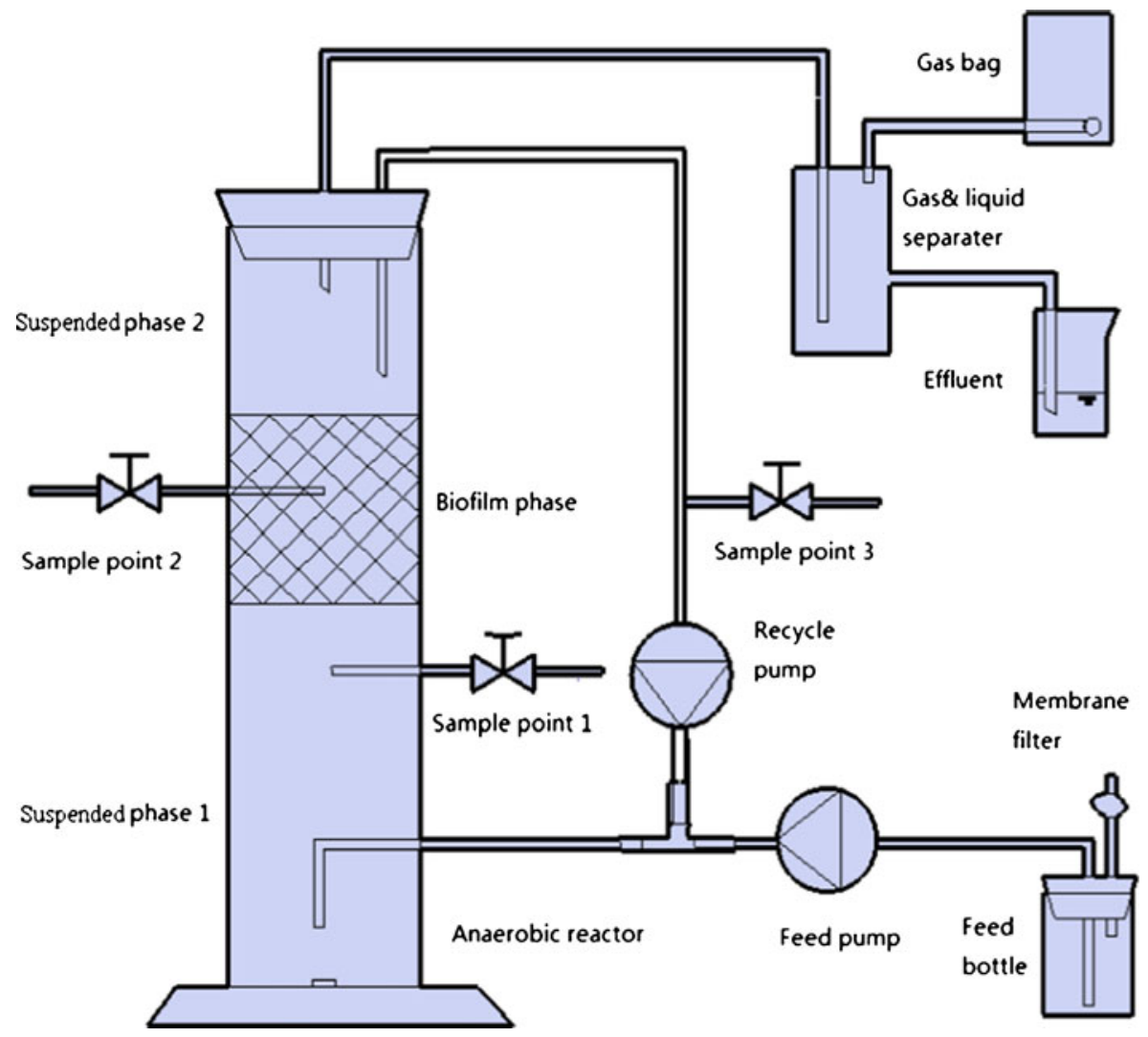

Fig. 1 Schematic configuration of the anaerobic hybrid reactor system [9] 
Toxicity Tests

The toxicity tests were performed in accordance with the standard procedures described in the OECD guidelines OECD201, OECD 202 and OECD draft guideline 'zebra fish embryo toxicity test' [12]. Pure MEA (PM), reclaimer MEAw and TW (AD effluent) were used as test substrates. A brief description of each test is provided.

Growth inhibition of the algae $P$. subcapitata was performed in accordance with OECD guideline 201 [12]. A fully defined growth medium was used (OECD TG201). Cell counts were performed every $24 \pm 2 \mathrm{~h}$ for the duration of the test with a Beckman Coulter Multisizer 3 (Beckman Coulter, USA). There were six control replicates and three replicates per test concentration. Test concentrations were made from dilution of a stock solution and inoculated with an algal culture in exponential growth to a concentration of $5 \times 10^{3}$ cells $\mathrm{mL}^{-1}$. The tests were incubated at $20 \pm 2{ }^{\circ} \mathrm{C}$ on an orbital shaker in continuous light from cool white fluorescent tubes (Philips TLD $36 \mathrm{~W} / 950$ ). The average growth rate for each test concentration was calculated from initial cell concentration and cell concentration at the time of the last cell count using the equation:

$$
\mu=\frac{\ln \left(N_{\mathrm{n}}\right)-\ln \left(N_{0}\right)}{t_{\mathrm{n}}-t_{0}}
$$

$N_{\mathrm{n}}=$ cell density at time $t_{\mathrm{n}}, N_{0}=$ cell density at time zero $\left(t_{0}\right)$

The percentage inhibition of growth rate as compared to the control was calculated for each treatment. Effect concentration values were determined with non-linear regression analysis using a Microsoft Excel macro, 'REGTOX' [14].

Acute immobilisation of D. magna was performed in accordance with OECD guideline 202 [15]. Five neonates ( $<24 \mathrm{~h}$ old) were added to the test vessels containing $40 \mathrm{ml}$ of test media. Four replicates were used per test concentration. Test vessels were examined under the microscope every $24 \mathrm{~h}$ for the duration of the test $(48 \mathrm{~h})$ and immobilised or dead animals in each treatment were recorded. The $\mathrm{EC}_{50}$ values were calculated with non-linear regression analysis.

Embryos of the zebra fish, D. rerio, were obtained from the Norwegian Veterinary Institute, Oslo. The test method was based on the OECD draft guideline 'zebra fish embryo toxicity test'. The test was initiated immediately after fertilisation and continued for $96 \mathrm{~h}$ in duration. Lethal effects were recorded every $24 \mathrm{~h}$ and were based on four apical observations including: coagulation of the embryo, non-detachment of the tail, non-formation of somites and nondetection of the heartbeat. Observations of any one of these four malformations were indicative of lethality. This was compared to the occurrence in the dilution water control to provide sufficient information to calculate lethal concentration (LC) toxicity endpoints.

The physiochemical properties of MEAw and TW are given in Table 2, where properties of feed MEAw + co-substrate are also provided.

\section{Results and Discussion}

Anaerobic digestion results presented below were obtained and analysed at an OLR of $1.6 \mathrm{~kg} \mathrm{COD} \mathrm{m}^{-3}$ day $^{-1}$ and a MEAw ratio of 0.59 (COD based).

\section{Anaerobic Digestion of MEAw}

Methane yield, ammonia level and other reactor performance parameters at steady state process operation when samples for the toxicity tests were taken is shown in Table 3. 
Table 2 Measured parameter values of the three waste mixtures

\begin{tabular}{llll}
\hline Parameter $(\mathrm{g} / \mathrm{L})$ & MEAw (reclaimer MEAw) & Feed MEAw + co-substrate & TW (AD effluent) \\
\hline $\mathrm{COD}$ & 700 & 30.3 & 3.4 \\
$\mathrm{NH}_{4}$ & 0.8 & 0.01 & 2.4 \\
$\mathrm{~K}^{\mathrm{a}}$ & - & 0.23 & 0.19 \\
$\mathrm{Na}$ & 68.8 & 1.1 & 0.9 \\
$\mathrm{pH}$ & 11.1 & 9.8 & 7.9 \\
Conductivity & 11.3 & 6.2 & 15.2 \\
Salinity & 4.8 & 2.8 & 8.5 \\
\hline
\end{tabular}

COD chemical oxygen demand

${ }^{a}$ Due to the high chemical oxygen demand, the waste water mixtures required dilution by 10,000 times its original concentration before analysis. This dilution resulted in $[\mathrm{K}]$ falling below the detection limit and is not reported

Table 3 shows a methane yield of $0.2 \mathrm{~L} / \mathrm{g}$ COD and a volatile fatty acid (VFA) concentration of $114 \mathrm{mg} \mathrm{COD} / \mathrm{L}$, where acetic acid constitutes over $90 \%$ of the VFA. The released methane and accumulated VFA are degradation products of the feed and are about $63 \%$ of the total feed COD.

The digester was running at stable conditions with $\mathrm{pH}$ at around 7.9, which was considered suitable for methanogenesis. The total ammonia nitrogen (TAN $=\mathrm{NH}_{4}{ }^{+}+\mathrm{NH}_{3}$ ) concentration was $2.0 \mathrm{~g} \mathrm{~N} / \mathrm{L}$ with a free ammonia, FAN, concentration of $68 \mathrm{mg} \mathrm{N} / \mathrm{L}$. Ammonia concentrations gradually increased during the 2 years of reactor operation prior to this test and degradation of MEAw was the main source of ammonia $[9,10]$.

\section{Ecotoxicity}

The results of the toxicity tests for pure MEA, MEAw and TW (Table 3) on the three trophic groups are given in Table 4. It shows that the algae were the most sensitive of the three tested species to the pure MEA and MEAw, followed by daphnids and zebra fish embryos. Zebra fish embryos were the most sensitive group to TW, followed by algae and daphnids, although the sensitive concentrations of TW were quite close for all three.

Table 3 Parameter values of the steady state operation $\mathrm{AD}$ during the study

${ }^{\text {a }}$ Standard deviations in the bracket

\begin{tabular}{lll}
\hline Parameter & Units & Values $^{\mathrm{a}}$ \\
\hline OLR & kg COD m & \\
MEAw day & & \\
Feed COD & MEAw COD/total COD & 0.59 \\
Feed amount & $\mathrm{g} \mathrm{COD} / \mathrm{L}$ & 22.5 \\
$\mathrm{CH}_{4}$ yield & $\mathrm{mL} /$ day & 88 \\
Total ammonia nitrogen & $\mathrm{g} / \mathrm{g} \mathrm{COD}$ added & $0.20(0.02)$ \\
$\quad\left(\mathrm{NH}_{4}{ }^{+}+\mathrm{NH}_{3}\right)$ & $\mathrm{mg} \mathrm{N} / \mathrm{L}$ & $2.0(0.4)$ \\
Free $\mathrm{NH}_{3}$ & - & $68(19)$ \\
pH & $\mathrm{mg} \mathrm{COD} / \mathrm{L}$ & $7.9(0.1)$ \\
VFA & $\mathrm{g} \mathrm{COD} / \mathrm{L}$ & $114(37)$ \\
Effluent COD & Percentage & $3.4(0.6)$ \\
Removal efficiency & & $85.9(0.9)$ \\
\hline
\end{tabular}


Table 4 Summary of ecotoxicity endpoints for the three test chemicals corresponding to the three trophic groups

\begin{tabular}{lllll}
\hline Test chemical & Trophic group & $\mathrm{EC}_{10}{ }^{\mathrm{a}}$ & $\mathrm{EC}_{50}{ }^{\mathrm{a}}$ & $\mathrm{COD}_{(\mathrm{mg} \text { COD/L) }}{ }^{\mathrm{b}}$ \\
\hline MEA $(\mathrm{mg} / \mathrm{L})$ & Algae & 30 & 151 & 198 \\
& Daphnids & 128 & 209 & 274 \\
& Zebra fish & 165 & 618 & 809 \\
MEAw $(v / v \%)$ & Algae & 0.0089 & 0.019 & 0.15 \\
& Daphnids & 0.060 & 0.081 & 0.61 \\
TW $(v / v \%)$ & Zebra fish & 0.034 & 0.194 & 1.54 \\
& Algae & 0.74 & 2.4 & 81.5 \\
& Daphnids & 2.2 & 3.4 & 116 \\
& Zebra fish & - & 1.91 & 64.9 \\
\hline
\end{tabular}

${ }^{a} \mathrm{ECx}$ : the concentration which results in $\mathrm{x}$ percentage reduction in growth rate, immobilisation or lethal effects compared to the control

${ }^{\mathrm{b}}$ At $\mathrm{EC}_{50}$

The $50 \%$ growth rate inhibition $\left(\mathrm{EC}_{50}\right)$ for unicellular algae, $50 \%$ acute immobilisation for crustacean D. magna and $50 \%$ lethal effects concentrations for embryos of the zebra fish were observed at MEA concentrations of 151, 209 and $618 \mathrm{mg} / \mathrm{L}$, respectively. MEA constituted $18 \mathrm{wt} \%$ and was the main chemical identified in the MEAw used. Based on the calculation, the MEA concentration in the feed substrate was $4 \mathrm{~g} / \mathrm{L}$, which is much higher than the observed $\mathrm{EC}_{50}$ thresholds for the tested tropic groups.

MEAw had much stronger toxic effects than just MEA (Table 4). The $\mathrm{EC}_{50}$ for the three trophic groups were observed to be at MEAw dilution ratios of 5,000, 1,250 and 500, corresponding to MEAw concentrations of $0.24,0.98$ and $2.44 \mathrm{mg} / \mathrm{L}$, respectively. The MEA concentrations were calculated to be $0.04,0.18$ and $0.44 \mathrm{mg} / \mathrm{L}$, respectively at the three MEAw $\mathrm{EC}_{50}$ concentrations. These levels were much lower than the pure MEA EC $\mathrm{EC}_{50}$ concentrations (Table 4). MEAw evidently contains more additional toxic substances other than MEA. MEAw contains a mixture of chemicals, and some have been identified [4, 5], whilst the chemical composition is often dependent on which analytical method and/or instrumentation is applied [16]. The information on toxicity effects of the detected chemicals is limited. It is expected that MEA degradation of organic and inorganic salts $(10 \mathrm{wt} \%)$ in the waste due to the addition of sodium carbonate, in addition to corrosion products generated and inorganic anions formed from compounds in the flue gas (nitrate from NOx and sulphate from SOx) contributed to the toxicity effects of MEAw.

The COD concentrations were calculated for MEA, MEAw and TW at their $\mathrm{EC}_{50}$ for each trophic group (Table 4). MEAw COD concentrations at their $\mathrm{EC}_{50}$ were the lowest in the test chemicals. It indicates that if the toxicity was caused by organic components, then their concentrations were at relatively low levels. Inorganic materials $\left(\mathrm{e} . \mathrm{g} . \mathrm{NH}_{3}\right)$ that cannot be oxidised by dichromate may have also contributed to the observed toxicity.

The toxicity test of TW for the three trophic groups shows that the $\mathrm{EC}_{50}$ concentrations increased 126, 42 and 10 times after anaerobic treatment comparing to that of MEAw (Table 4). The remaining toxicity in TW after AD is not due to MEA since MEA was not detected in effluent samples due to biodegradation (Fig. 2) [9]. Some unidentified chemicals in MEAw were also degraded to below detection levels in the effluent samples. Ammonia was the major degradation product in the effluent water detected by ion chromatography (Fig. 2). Unidentified toxic organics in the effluent after the AD that are suspected to inhibit 
Fig. 2 IC analysis of samples: black line effluent (50 times diluted), red line co-digestion organics (50 times diluted), green line feed substrate (50 times diluted), and blue line $1 \mathrm{~g}$ MEA waste (1,000 times diluted) [9]

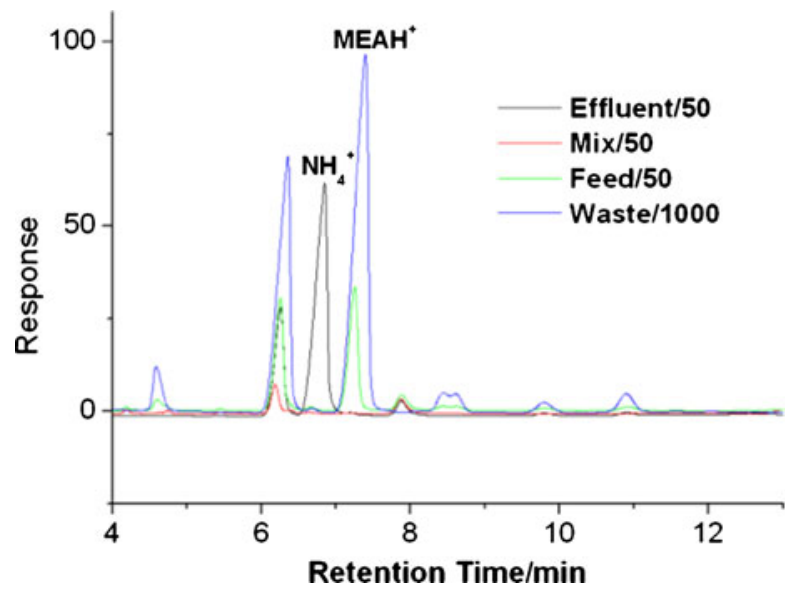

methanogenesis at high feed loads [10] may also contribute to the toxicity in TW after AD observed here.

The TW COD concentrations corresponding to the $\mathrm{EC}_{50}$ were much higher than that of MEAw (Table 4), suggesting that toxic organic substances were removed by AD. VFAs, mainly acetic acid, were the main organics detected in TW (Table 3). Although COD is not a standardised unit for assessing toxicity effects, it can be used as a proxy for organic substances, and variations in COD may indicate changes of toxic components. Toxic components from MEAw may have been degraded, while inert and residual (14\% of feed COD) components and ammonia from the feed substrates degradation may contribute to the remaining toxicity to the tested trophic groups.

TW toxicities to the three trophic groups show that $\mathrm{EC}_{50}$ were not significantly different (Table 4). TAN $\left(\mathrm{NH}_{4}{ }^{+}\right.$and $\mathrm{NH}_{3}$ ) and FAN concentrations that were above 2.0 and $68 \mathrm{mg} \mathrm{N} / \mathrm{L}$, respectively (Table 3 ) in the TW can potentially be the main cause of the observed remaining toxicity of TW. Low ammonia can be beneficial to aquatic organisms (e.g. algae), but elevated ammonia concentrations in the aquatic environment are toxic. The negative impacts of ammonia can be due to inhibiting photosynthesis of algae [17, 18], damaging fish gill epithelium, repressing immune system, disrupting blood vessels, etc. [19].

The threshold concentrations of TAN in freshwater that result in unacceptable biological effects were suggested to be $3.48 \mathrm{mg} \mathrm{N} / \mathrm{L}$ at $\mathrm{pH} 6.5$ and $0.25 \mathrm{mg} \mathrm{N} / \mathrm{L}$ at $\mathrm{pH} 9.0$ [20]. Free ammonia $\left(\mathrm{NH}_{3}\right)$, however, is considered to be more toxic to aquatic animals than ionised ammonia. Concentrations of less than $0.05-0.35 \mathrm{mg} \mathrm{NH}_{3}-\mathrm{N} / \mathrm{L}$ for short-term exposures and less than $0.01-0.02 \mathrm{mg} \mathrm{NH}-\mathrm{N} / \mathrm{L}$ for long-term exposures have been recommended to protect aquatic animals [19]. TW that gave $\mathrm{EC}_{50}$ for algae was at TAN and FAN concentrations of 49 and $1.6 \mathrm{mg} \mathrm{N} / \mathrm{L}$, respectively. The value was 69 and $2.3 \mathrm{mg} \mathrm{N} / \mathrm{L}$, respectively, for Daphnids, which was quite close to the $\mathrm{FAN} \mathrm{EC}_{50}$ concentration (2.94 $\mathrm{mg} \mathrm{N} / \mathrm{L}$ ) observed by Gersich and Hopkins [21]. The TW $\mathrm{EC}_{50}$ for embryos of the zebra fish had TAN and FAN concentrations of 102 and $3.4 \mathrm{mg} \mathrm{N} / \mathrm{L}$, respectively. Both the TAN and FAN concentrations of TW (Table 3) were much higher than that proposed for environmental protection and close to the acute toxicity of the free ammonia concentration. This implies that the observed toxicity of TW can be largely due to high ammonia concentration in the TW. A proper post-treatment of the anaerobic digester effluents to reduce ammonia content, such as by nitrification, can therefore potentially eliminate or reduce the waste toxicity to lower levels. 


\section{Conclusion}

The toxicity of MEAw was reduced by 10 to 126 times by anaerobic digestion at steady state by an adapted culture, shown as 126, 42 and 10 times higher $\mathrm{EC}_{50}$ tolerance concentrations of digester effluents than for the untreated MEAw to three freshwater trophic groups. The remaining toxicity of the treated MEAw can largely be attributed to ammonia generated from MEAw degradation. Other toxic constituents may, however, also survive AD of MEA reclaimer waste. Anaerobic digestion of MEAw combined with ammonia removal can potentially reduce the environment toxicity to enable safe effluent discharge.

Acknowledgments The Research Council of Norway (Climit Programme) and the industry partners, Hydro Aluminium AS, Noretyl AS, Norcem AS, NOAH AS, E.On Sverige AB, Elkem Thamshavn AS and Aker Clean Carbon AS are acknowledged for their support.

Open Access This article is distributed under the terms of the Creative Commons Attribution License which permits any use, distribution, and reproduction in any medium, provided the original author(s) and the source are credited.

\section{References}

1. Pacala, S., \& Socolow, R. (2004). Science, 305(5686), 968-972.

2. Singh, B., Strømman, A. H., \& Hertwich, E. (2011). International Journal Greenhouse Gas Conversion, 5(3), 457-466.

3. Brooks, S., \& Wright, R. (2008), NIVA Serial No.5698-2008. NIVA, Norway.

4. Strazisar, B. R., Anderson, R. R., \& White, C. M. (2003). Energy \& Fuels, 17(4), 1034-1039.

5. Thitakamol, B., Veawab, A., \& Aroonwilas, A. (2007). International Journal Greenhouse Gas Conversion, 1(3), 318.

6. Eide-Haugmo, I., Brakstad, O. G., Hoff, K. A., Sørheim, K. R., Da Silva, E. F., \& Svendsen, H. F. (2009). Energy Procedia, 1(1), 1297-1304.

7. EU (2000), Official Journal of the European Union, L226, 6.9.2000.

8. Council Directive 91/689/EEC of 12 December 1991 on hazardous waste Official Journal L 377, 31/12/ 1991 P. 0020 - 0027.

9. Wang, S., Hovland, J., \& Bakke, R. (2013). Water Science and Technology, 67(11), 2549-2559.

10. Wang, S., Hovland, J., \& Bakke, R. (2013) Biotechnol. Lett. Accepted for publication.

11. Botheju, D., Li, Y., Hovland, J., Haugen, H. A., \& Bakke, R. (2011). Energy Procedia, 4, 496-503.

12. OECD. (2011). Guidelines for testing of chemicals. No. 201; Alga. Growth inhibition test. Paris: OECD.

13. Strazisar, B. R., Anderson, R. R., \& White, C. M. (2001). Journal Energy Environmental Research, 1(1), 32-39.

14. Vindimian, E., Robaut, R., \& Fillion, G. (1983). Journal of Applied Biochemistry, 5, 261-268.

15. OECD. (2004). Guidelines for the testing of chemicals/section 2: effects on biotic systems test no. 202: Daphnia sp. acute immobilisation test. Paris: OECD.

16. Da Silva, E. F., Lepaumier, H., Grimstvedt, A., Vevelstad, S. J., Einbu, A., Vernstad, K., Svendsen, H. F., \& Zahlsen, K. (2012). Industrial and Engineering Chemistry Research, 51(41), 13329-13338.

17. Abeliovich, A., \& Azov, Y. (1976). Applied and Environmental Microbiology, 31, 801-806.

18. Azov, Y., \& Goldman, C. (1982). Applied and Environmental Microbiology, 43, 735-739.

19. Camargo, J. A., \& Alonso, A. (2006). Environmental International, 32, 831-849.

20. Ip, Y. K., Chew, S. F., \& Randall, D. J. (2001). In P. A. Wright \& P. M. Anderson (Eds.), Fish physiology, Vol 20: nitrogen excretion (pp. 109-148). New York: Academic.

21. Gersich, F. M., \& Hopkins, D. L. (1986). Environmental Toxicology and Chemistry, 5, 443-447. 